\title{
Clinical Experience with Bethanidine in Treatment of Hypertension*
}

\author{
JULIAN BATH, M.B., B.SC., M.R.C.P.ED. ; DOUGLAS PICKERING, M.B., M.R.C.P.ED. \\ RICHARD TURNER, M.D., F.R.C.P., F.R.C.P.ED.
}

Brit. med. F., 1967, 4, 519-521

At the present time probably most patients with high blood pressure in this country are being treated with guanethidine or methyldopa with or without the addition of an oral diuretic. Because of certain disadvantages of these two drugs in our experience (Lowther and Turner, 1963 ; Johnson et al., 1966) we have largely confined our attention during the past three years to debrisoquine (Kitchin and Turner, 1966) and bethanidine. Experience with the latter drug is the subject of this paper.

\section{Pharmacology}

Bethanidine is a post-ganglionic adrenergic neurone-blocking agent which exerts a marked postural hypotensive effect (Boura et al., 1961 ; Boura and Green, 1963 ; Fewings et al., 1964). In man sympathetic blockade begins about two hours after a single dose, is maximal in four to five hours, and fades in 8 to 12 hours, but the duration of action depends on the dose administered (Smirk, 1963 ; Johnston et al., 1964 ; Wilson et al., 1965). The absorption and excretion of ${ }^{14} \mathrm{C}$ bethanidine in man was studied by Doyle and Morley (1965), who showed that after oral administration absorption was rapid and almost complete. Excretion is almost entirely in the urine, the rate depending on the glomerular filtration rate. Other studies have shown the renal clearance of inulin and of paraaminohippuric acid to be slightly reduced in patients given bethanidine (Esch and Krammer, 1965).

The precise mechanism whereby bethanidine causes blockade of adrenergic neurones is unknown (Boura and Green, 1965). An initial sympathomimetic effect has been demonstrated in man and animals, possibly due to release of catecholamines, for it is blocked by phenoxybenzamine (Fewings et al., 1964), and increased sensitivity to noradrenaline after bethanidine further suggests peripheral release of catecholamines by this drug. Bethanidine resembles bretyliumtosylate and debrisoquine in that blockade is achieved without early depletion of tissue catecholamines, in this respect differing from guanethidine and guanoclor. However, large doses of bethanidine over long periods reduce catecholamines in some tissues (Boura et al., 1961). Unless administered in very high concentration bethanidine does not block cholinergic or motorneurone activity (Boura and Green, 1963).

\section{Material and Methods}

Between September 1964 and March 196770 patients were treated with bethanidine for periods ranging from six to 24 months : 23 were followed up for six to 12 months, 10 for 13 to 18 months, 22 for 19 to 24 months, and 15 for 25 to 30 months. In addition 12 patients stopped treatment earlier for reasons discussed below. Ages ranged from 21 to 66 years. Of the 82 patients 41 were made and 41 female. Table I includes the age distribution related to severity of the disease.

Indications for treatment, selection of patients, methods of blood pressure measurement, criteria of severity, and classification of results were similar to those we have already described in relation to the other drugs except that this series includes more relatively young patients without evidence of secondary changes in the heart or fundi.

Half the patients had previously received treatment with other antihypertensive drugs. Most new patients were admitted to hospital for assessment of the severity and type of their hypertension and the initiation of appropriate treatment. In some who had been fully assessed previously and treated for * University Department of Medicine and the Cardiac Department of the
Western General Hospital, Edinburgh 4 . a period with other drugs the change-over was arranged on an outpatient basis. The usual reason for change was difficulty in controlling the blood pressure, undue postural hypotension, or side-effects.

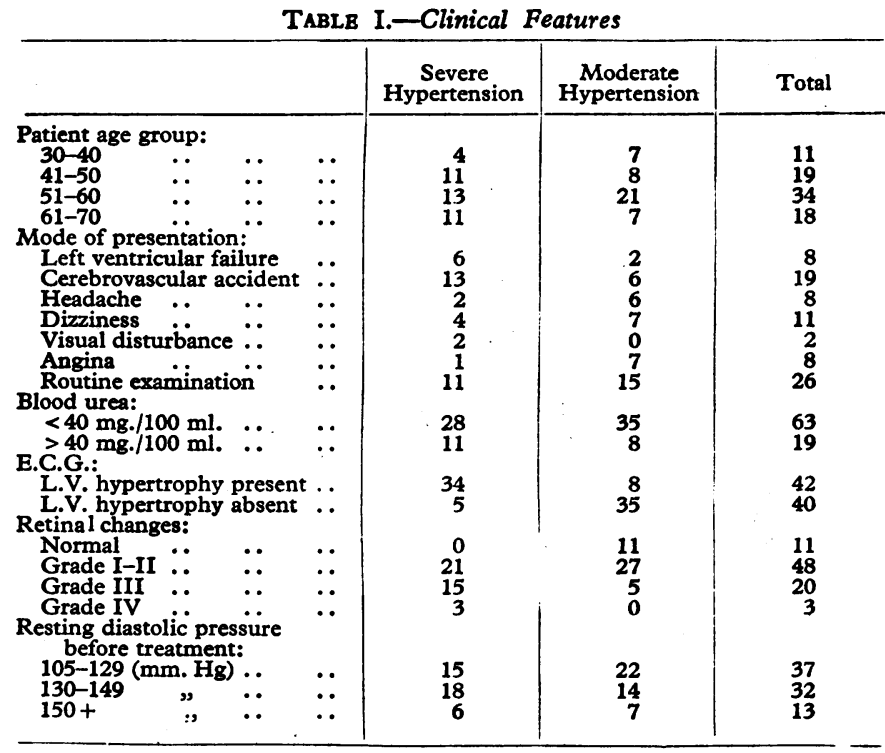

The initial dose of bethanidine was usually $5 \mathrm{mg}$. twice daily. Increments were made every third day in hospital patients and every week in those being treated at home until an adequate response was obtained. Frequency of attendance at the clinic depended on the degree of control or the presence of side-effects. The daily dose ranged from 10 to $120 \mathrm{mg}$., with an average of $32.5 \mathrm{mg}$. in the initial stages and $43 \mathrm{mg}$. later on.

As in previous studies of antihypertensive drugs the aim of treatment was to reduce the standing diastolic pressure to as near normal levels as could be achieved without undue sideeffects. In patients with cerebral or coronary atherosclerosis or with a persistently raised blood urea the blood pressure was lowered more cautiously and reduction to a standing diastolic level of $100-105 \mathrm{~mm}$. Hg was regarded as a satisfactory result. Only the fall in pressure achieved and maintained has been considered in classifying the results of treatment. A " good" result signifies a fall in diastolic pressure to below $100 \mathrm{~mm}$. $\mathrm{Hg}$. A "fair" result signifies a fall of diastolic pressure to between 100 and $110 \mathrm{~mm}$. Hg. A "poor" result denotes failure to maintain a diastolic pressure below $110 \mathrm{~mm}$. $\mathrm{Hg}$. It will be appreciated that a precise classification is not possible because in some patients the deliberate aim has been to achieve a fair result as defined by reduction in blood pressure.

The results have been tabulated for each patient at intervals of six months.

\section{Results}

Of the original 82 patients, four died, seven discontinued bethanidine because of side-effects, and one defaulted before the end of six months. The remaining 70 all completed at least six months of treatment (Table II).

After six months one patient discontinued the drug because of side-effects, two defaulted, and seven died. At the end of 


\begin{tabular}{|c|c|c|c|c|c|}
\hline & \multirow{2}{*}{ Control } & \multicolumn{2}{|c|}{ Patients } & \multicolumn{2}{|c|}{ Total } \\
\hline & & Moderate & Severe & No & $\%$ \\
\hline At 6 months & $\begin{array}{l}\text { Good } \\
\text { Fair } \\
\text { Poor }\end{array}$ & $\begin{array}{r}15 \\
13 \\
9\end{array}$ & $\begin{array}{c}15 \\
88 \\
10\end{array}$ & $\begin{array}{l}30 \\
21 \\
19\end{array}$ & $\begin{array}{l}3 \\
30 \\
27\end{array}$ \\
\hline At 12 months & $\begin{array}{l}\text { Good } \\
\text { Fair } \\
\text { Poor }\end{array}$ & $\begin{array}{r}12 \\
10 \\
3\end{array}$ & $\begin{array}{r}12 \\
3 \\
7\end{array}$ & $\begin{array}{l}24 \\
13 \\
10\end{array}$ & $\begin{array}{l}52 \\
28 \\
20\end{array}$ \\
\hline At 18 months & $\begin{array}{l}\text { Good } \\
\text { Fair } \\
\text { Poor }\end{array}$ & $\begin{array}{r}13 \\
5 \\
2\end{array}$ & $\begin{array}{l}8 \\
3 \\
6\end{array}$ & $\begin{array}{r}21 \\
8 \\
8\end{array}$ & $\begin{array}{l}56 \\
22 \\
22\end{array}$ \\
\hline At 24 months & $\begin{array}{l}\text { Good } \\
\text { Fair } \\
\text { Poor }\end{array}$ & $\begin{array}{l}4 \\
3 \\
1\end{array}$ & $\begin{array}{l}5 \\
1 \\
1\end{array}$ & $\begin{array}{l}9 \\
4 \\
2\end{array}$ & $\begin{array}{l}60 \\
27 \\
13\end{array}$ \\
\hline
\end{tabular}

six months $73 \%$ of patients had good or fair control of their blood pressure. Results improved with continued treatment and adjustment of dosage with or without the addition of an oral diuretic, the proportion having good or fair control rising to $80 \%$ after 12 months and to $87 \%$ in the 15 patients who had been treated for two years. Most of the poor results were in patients with severe hypertension.

Of the 19 patients in whom initial control was unsatisfactory 13 continued treatment for 12 months or more. Good or fair control was achieved in five by increasing the dose and in three more by the addition of an oral diuretic. Of the five patients in whom control was persistently poor two had severe cerebral atherosclerosis, one uraemia, one asthma requiring corticosteroid therapy, and one cor pulmonale. Temporary failure of control was attributed to tolerance in two patients and to side-effects in two others. Of nine patients with only fair control throughout, two had severe cerebral atherosclerosis, five side-effects, and one a rising blood urea.

\section{Deaths}

Eleven patients died during treatment, but in none was this thought to be attributable to the drug being used or to failure to maintain reasonable control over the blood pressure or to side-effects. Three died from myocardial infarction, three from cerebral haemorrhage, and two from uraemia. In addition, one died from rupture of an aortic aneurysm and one suddenly from an unknown cause.

Four patients had been under treatment for three months or less, four for 8 to 14 months, and three for approximately 18 months. Seven had previously shown evidence of coronary or cerebral atherosclerosis.

\section{Side-effects}

Thirty-one patients (38\%) had symptoms from postural hypotension, but in most cases this was relieved by adjustment of dosage while still maintaining satisfactory control over the blood pressure. A few had syncope and in five bethanidine had to be discontinued.

As is usual with drugs which lower blood pressure by sympathetic blockade the lowest readings were recorded first thing in the morning or when special readings were taken during what are normally sleeping hours. It is of interest in this connexion that several patients complained of syncope or dizziness after rising at night to pass urine.

Transient focal neurological disturbances associated with postural hypotension were recorded in two patients, but in none of the six whose death was attributable to a cerebral vascular accident or in the two patients who died of renal failure had there been excessive hypotension.

Five patients complained of muscular weakness soon after starting treatment and in two the drug was discontinued. Two who complained of impotence had previously experienced this symptom when taking other antihypertensive drugs. There was no case of diarrhoea or of mental depression. Two patients developed cardiac failure while on treatment, but this was attributable to the underlying heart disease.
The incidence of side-effects bore no obvious relation to the initial severity of hypertensive disease, the presenting symptoms, associated atherosclerosis, the degree of blood pressure control, or subsequent death. As with other antihypertensive drugs the incidence between individuals was most variable.

\section{Oral Diuretic Supplements}

In order to facilitate comparison with other drugs it had been intended, if possible, to treat all patients with bethanidine alone. However, it became necessary to add an oral diuretic in 28 cases on account of difficulty in controlling the pressure, side-effects, or fluid retention.

As can be seen from Table III the mean daily dose of bethanidine was gradually increased for most patients. In 19 cases the dose was increased to improve control and in seven to regain control on account of tolerance. An oral diuretic was added to improve control in six and to regain control in two patients. The fact that supplementary oral diuretics were used in $34 \%$ of all patients reflects the difficulty experienced in achieving satisfactory control with freedom from excessive postural hypotension when using bethanidine alone. In a few cases a diuretic was used from the start because rapid control of the blood pressure or a diuresis was required. Diuretics were used in a proportionately larger number of patients the longer treatment continued, because of an increased tendency to make this addition whenever difficulty with control or sideeffects was experienced.

\begin{tabular}{c|c|c} 
TABLE III.-Average & $\begin{array}{c}\text { Dose of Bethanidine According to Duration of } \\
\text { Treatment }\end{array}$ \\
\hline \begin{tabular}{c|c|c} 
Duration of Treatment \\
(months)
\end{tabular} & No. of Patients & $\begin{array}{c}\text { Average Dose Bethanidine } \\
\text { (mg.) }\end{array}$ \\
\hline 3 & 77 & $32 \cdot 5$ \\
6 & 70 & 37 \\
12 & 47 & 40 \\
18 & 37 & 43 \\
\hline 24 & 15 & 45 \\
\hline
\end{tabular}

\section{Comparison of Guanethidine, Methyldopa, Debrisoquine, and Bethanidine}

Since the treatment of hypertension with guanethidine, methyldopa, and debrisoquine has previously been described from our unit some comparison between these drugs can be made. Recently, however, there has been a decreased incidence of severe hypertensive disease and a progressive tendency to treat patients who have relatively mild hypertensive disease. It is no longer thought desirable to carry out double-blind trials of different drugs in the same patient because of greater ease of controlling the blood pressure. All that is required is to change treatment to another preparation in any patient not doing well on a particular drug.

Table IV shows the results of treatment in groups of patients thought to have hypertensive disease of comparable severity according to the criteria described. Seventy-three with severe hypertension were treated with guanethidine, 37 with methyldopa, 31 with debrisoquine, and 26 with bethanidine, all for more than six months and many for as long as 18 months. The same criteria were used in classifying results on the basis of blood pressure control. It will be seen that there is no striking difference in the results of treatment with the four

TABLE IV.-Comparison of Long-term Results and Supplementary Use of Oral Diuretics in Treatment of Severe Hypertension with Guanethidine, Methyldopa, Debrisoquine, and Bethanidine

\begin{tabular}{|c|c|c|c|c|}
\hline Control & $\begin{array}{l}\text { Guanethidine } \\
73 \text { Patients }\end{array}$ & $\begin{array}{l}\text { Methyldopa } \\
37 \text { Patients }\end{array}$ & $\begin{array}{l}\text { Debrisoquine } \\
31 \text { Patients }\end{array}$ & $\begin{array}{l}\text { Bethanidine } \\
26 \text { Patients }\end{array}$ \\
\hline \multirow{2}{*}{ 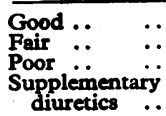 } & $\begin{array}{l}40 \% \\
40 \% \\
20 \%\end{array}$ & $\begin{array}{l}54 \% \\
33 \% \\
13 \%\end{array}$ & $\begin{array}{r}71 \% \\
22 \% \\
7 \%\end{array}$ & $\begin{array}{l}70 \% \\
15 \% \\
15 \%\end{array}$ \\
\hline & $56 \%$ & $41 \%$ & $65 \%$ & $38 \%$ \\
\hline
\end{tabular}


preparations. About $50 \%$ of patients on guanethidine, about $40 \%$ each with methyldopa and bethanidine, and about $65 \%$ with debrisoquine, required the addition of an oral diuretic. This probably reflects a somewhat greater degree of tolerance to debrisoquine, but on the other hand, as discussed below, postural symptoms and side-effects were least with this preparation.

\section{Discussion}

The rapid onset of the antihypertensive effect after oral administration of bethanidine and the short duration of action are obvious advantages when reduction of blood pressure is required as an emergency or when an excessive hypotensive effect has to be counteracted quickly. In the two instances in which we have used oral bethanidine to gain rapid control of malignant hypertension a satisfactory response was obtained within the first 24 hours.

In long-term treatment fair or good control was obtained In 73 to $87 \%$ of patients, depending on the duration of treatment. These results are similar to those reported by Montuschi and Pickens (1962), who used supplementary oral diuretics in over half their patients, and by Johnston et al. (1964), who used oral diuretics in less than $20 \%$ of cases. In the report by Smirk (1963) the assessment of results was rather different, but approximately $60 \%$ of 56 patients were controlled with bethanidine alone. Esch and Krammer (1965) obtained a satisfactory result in 35 out of 40 outpatients, using supplementary oral diuretics only occasionally.

The chief difficulty we have encountered is postural hypotension, which is most likely to occur in the initial phases of treatment when quite pronounced fluctuations of standing blood pressure may occur. Postural symptoms may be particularly troublesome in the morning, and in those who for any reason have to get out of bed at night. The fall in pressure which follows micturition may be an additional factor in some cases. Postural hypotension is also particularly apt to develop after the addition of an oral diuretic unless care is taken to make an adequate reduction in the dose of bethanidine. We have the impression that this may occur more readily than with other antihypertensive drugs but that smoother control may sometimes be achieved by suitable timing of the doses of bethanidine given three or four times during the 24 hours, depending on individual requirements. Since bethanidine has considerable advantages in other respects persistence is well worth while because satisfactory control can usually be achieved.

Possibly each patient should first be treated for three to four weeks with an oral diuretic, after which time it is known that there is no further reduction in exchangeable sodium and that plasma and extracellular fluid volumes rise to previous levels, though the antihypertensive action of the diuretic persists (Peters, 1966).

However, the long-term administration of oral diuretics in the treatment of hypertension depletes the body not only of sodium but of potassium and other ions, including magnesium, 80 that many would prefer not to use them routinely. In all cases it is only sensible to reduce the intake of salt.

The dose of drug required to maintain control increased in many patients after they left hospital, but tolerance with bethanidine is not a serious problem and can always be overcome. After three to six months, when smooth control had been obtained, a further increase in dosage or the addition of an oral diuretic was required in about one-third of patients, but increments were usually small and after 18 months the need for a further increase was exceptional. It would therefore appear that tolerance is less of a problem in long-term management of hypertension with bethanidine than with debrisoquine. On the other hand, good control of the blood pressure during the first six months of treatment was achieved in a higher proportion of patients with debrisoquine and there was a lower incidence of side-effects. If in the first few months control can be achieved with bethanidine without undue postural effects it is likely to remain satisfactory.

In our experience the disadvantages of guanethidine included the difficulty in adjustment of dosage because increments were so critical, the frequency and disabling nature of side-effects, postural hypotension and syncope of effort, and the development of tolerance. With methyldopa side-effects were usually milder and less persistent, but many patients did not feel well ; also a number of severe toxic effects have now been reported, including Parkinsonism, hyperpyrexia, jaundice, and haemolytic anaemia.

Tolerance with debrisoquine and postural hypotension with bethanidine are relative disadvantages but less troublesome and disabling than the difficulties encountered with guanethidine or methyldopa.

There would now seem to be no case for beginning treatment with guanethidine or methyldopa in any new patient, but either may be useful in any patient in whom treatment with one of the newer preparations is unsatisfactory.

There can be no question that with the principal antihypertensive drugs in common use today, and with due attention to detail, the blood pressure can almost always be controlled satisfactorily, but some patients do better on one preparation than on another. It may be that instead of adding an oral diuretic there should be greater experiment with drugs in combination, and if any individual patient is not doing sufficiently well on debrisoquine or bethanidine a combination of these two preparations may well prove effective. Further experience is clearly required.

\section{Summary}

Seventy patients with hypertension were treated with bethanidine for periods ranging from six months to two years with satisfactory control of the blood pressure in about threequarters of them.

Toxicity was not seen and side-effects, apart from postural hypotension, were rare. Tolerance was not a problem.

Postural symptoms were experienced by $38 \%$ of all patients but could usually be overcome by adjustment of dosage and timing of drug administration or by combination with an oral diuretic.

For various reasons an oral diuretic was added in $34 \%$ of cases.

An attempt was made to compare the efficacy of guanethidine, methyldopa, debrisoquine, and bethanidine in groups of patients of similar severity as regards hypertensive disease.

It is concluded that bethanidine is a most useful addition to the drugs available for the treatment of hypertension, and, like debrisoquine, has advantages which outweigh relative disadvantages in comparison with guanethidine or methyldopa.

We thank Dr. N. L. Stokoe for reports on the retina of these patients; Miss M. Baker and Mrs. S. Heggie for carrying out numerous blood pressure readings; and Dr. A. D. Munro-Faure, of the Wellcome Foundation, for pharmacological advice.

\section{REFERENCES}

Boura, A. L. A., et al. (1961). Nature (Lond.), 191, 1312. and Green, A. F. (1963). Brit. F. Pharmacol., 20, 36 - and Green, A. F. (1965). Ann. Rev. Pharmacol., 5, 183.

Doyle, A. E., and Morley, A. (1965). Brit. F. Pharmacol., 24, 701.

Esch, I., and Krammer, J. (1965). Med. Klin., 60, 1859.

Fewings, J. D., Hodge, R. L., Scroop, G. C., and Whelan, R. F. (1964). Brit. f. Pharmacol., 23, 115.

Green, A. F., and Robson, R. D. (1964). Ibid., 22, 349.

Johnson, P., Kitchin, A. H., Lowther, C. P., and Turner, R. W. D. (1966)." Brit. med. ₹., 1, 133.

Johnston, A. W., Prichard, B. N. C., and Rosenheim, M. L. (1964). Lancet, 2, 659.

Kitchin, A. H., and Turner, R. W. D. (1966). Brit. med. ₹., 2, 728. Lowther, C. P., and Turner, R. W. D. (1963). Ibid., 2, 776.

Montuschi, E., and Pickens, P. T. (1962). Lancet, 2, 897.

Peters, G. (1966). In Symposium on Anti-hypertensive Therapy, edited by $\mathrm{F}$. Gross, p. 31 . Berlin.
.

Smirk, H. (1963). Lancet, 1, 743. Wilson, R., Long, C., and Jagoe, W. S. (1965), 7. Irish med. Ass., 56,
9. 